3. Commonwealth Department of Community Services and Health. National Women's Health Policy: Advancing Women's Health in Australia. Canberra: Australian Government Publishing Service, 1989.

4. Commonwealth of Australia, Sub-committee on Women and Health Australian Health Minister's Advisory Council. Health Goals and Targets for Australian Women. Canberra: Australian Government Publishing Service,1993.
5. Dixon J. Health Inequities Research Collaboration Framework. Canberra: National Centre for Epidemiology and Population Health, Australian National University, 1999.

6. Wilkinson R and Marmot M (eds). The Solid Facts: Social Determinants of Health. New York: World Health Organization., 1989.

7. Tilley, L (1996) Australian Health Outcomes Clearing House: Measuring Women's Health Outcomes - Gender Differences and Implications for Health Practice, November 1996. (Unpublished). $\mathbf{F}$

\title{
GENDER EQUITY IN HEALTH
}

Andrew Gow and Elena Murty

Health Services Policy Branch

NSW Department of Health

There is international and local recognition that social and economic factors play a significant role in determining health and well being. ${ }^{1,2,3}$ Recent policy developments by NSW Health in men's and women's health have been based on this recognition. This has led to the recent release of Moving Forward in Men's Health, ${ }^{4}$ and the soon to be released Strategic Framework to Advance the Health of Women. ${ }^{5}$ Both of these policy statements have also clearly recognised that gender is a social determinant of health.

The relationship between gender and health is often poorly understood. In an attempt to clarify this issue, the Department of Health is developing Gender Equity in Health. ${ }^{6}$ This document defines four key concepts:

- gender

- gender equity

- gender equality

- gender analysis.

It includes two checklists to be used as a tool to assist policy makers and service managers integrate these concepts into their work.

Gender Equity in Health explicitly states that gender equity is not another name for sex differentials. Sex differentials are essentially comparisons between men and women of factors such as health status and service usage. The effect of gender on health is generally not measured while sex differentials are. Sex differentials are often used to provide an indication (although an imperfect one) of the effect of gender and the need for gender equity.

Gender is a social construction. It refers to those roles, characteristics, responsibilities and expectations that our society ascribes as being male or female. Gender is socially determined, while sex is biologically determined. Gender equity, then, is a concept that recognises the differences in opportunities that are caused by gender, and brings about a range of strategies that aim to achieve fairness and justice in the distribution of the benefits and responsibilities. Gender equity is not about treating everyone the same. Rather, a gender equity approach involves examining which groups of women and which groups of men have poorer health outcomes than others. Different approaches may be required to attain equitable outcomes.

Gender equality is a more tangible concept. It is defined as the absence of discrimination, on the basis of sex rather than gender, in opportunities and the allocation of resources, benefits or access to services.

In order to encourage an improved understanding of the effect of gender on health, policy makers and service managers are encouraged to undertake gender analysis. This methodology analyses differences in opportunities, needs, incentives, circumstances, health status and quality of life in women and men. Gender analysis can be used to redress gender biases in policy, program design, management, implementation and review.

Gender Equity in Health will encourage a gender equity approach to health service policy planning and delivery across NSW.

\section{REFERENCES}

1. Wilkinson R and Marmot M (eds). Social Determinants of Health: The Solid Facts. Copenhagen: World Health Organization, 1998.

2. Royal Australasian College of Physicians. For richer, for poorer, in sickness and in health. Sydney: RACP, 1999.

3. Commonwealth Department of Health and Aged Care. (1999). Health Policy and Inequality. Canberra: Occasional Papers Unit, 1999.

4. NSW Department of Health. Moving Forward in Men's Health. Sydney: NSW Department of Health, 1999.

5. NSW Department of Health. Strategic Framework to Advance the Health of Women. Unpublished draft, 1999.

6. NSW Department of Health. Gender Equity in Health. Unpublished draft, 1999. it

Copies of Gender Equity in Health can be obtained from the Better Health Centre by telephoning (02) 98160452 and quoting publication number (HSP)000015; or from the Health Web site at www.health.nsw.gov.au. 